\title{
ATUAÇÃO DA ENFERMEIRA JUNTO AOS PACIENTES COM DISTÚRBIOS DO METABOLISMO HIDROSSALINO
}

\author{
Clarice Oliveira *
}

\begin{tabular}{l|l|} 
& $\mathrm{RBEn} / 04$ \\
\hline
\end{tabular}

OLIVEIRA, C. - Atuação da enfermeira junto aos pacientes com distúrbios do metabolismò hidrossalino. Rev. Bras. Enf., R.J., 28 : 52- 58, 1975.

\section{I - INTRODUÇÃO}

Metabolismo hidrossalino tem sido, nos últimos anos, assunto de constantes estudos e debates por parte dos profissionais da equipe de saúde. A complexidade, porém, de sua composição, envolvendo um mínimo domínio preciso dos princípios fundamentais da anátomo-fisiclogia dos liquidos orgânicos, bem como da aplicabilidade dos mesmos, no reconhecimento e atendimento dos distúrbios registrados no paciente, faz com que sejam necessárias freqüentes revisões e atualizações do tema.

O emprego dos conhecimentos concernentes ao assunto é indispensável desde o primeiro contato com o paciente. Podese mesmo afirmar que as alterações na dinâmica dos líquidos e eletrólitos estão presentes, em maior ou menor grau, em todos os estados patológicos.

Em pacientes graves estes distúrbios se apresentam com mais intensidade e os parâmetros fisiológicos são observados continuamente, a fim de que sejam detectadas, precocemente, quaisquer alterações, níveis considerados normais, dos elementos essenciais na manutenção do equilíbrio.

Com o surgimento das Unidades de Terapia Intensiva, as quais são, cada vez mais numerosas nos grandes centros urbanos, evoluem também os recursos tecnológicos. Estes tornam possível, verificações mais rápidas e mais sistemáticas de dosagens de elementos essenciais ao acompanhamento da evolução do paciente. Dentre eles os eletrólitos e os gases dissolvidos no plasma. Com tais recursos torna-se mais rápida $\mathrm{e}$ eficaz a assistência médica e de enfermagem nessas unidades. No entanto é necessário salientar que este desenvolvimento tecnológico não prescinde de pessoal preparado e sim passa a exigir muito maior categorização e especialização dos profissionais da área. Não se pode contar ainda, de maneira satisfatória, com este preparo na enfermagem, embora tenha-se que reconhecer o esforço de muitos, principalmente das enfermeiras que atuam em Unidades de Terapia Intensiva. A literatura específica

- Prof. Adjunto de Escola de Enfermagem da U.F.Ba. 
OLIVEIRA, C. - Atuação da enfermeira junto aos pacientes com distúrbios do metabolismo hidrossalino. Rev. Bras. Enf., R.J., 28 : 52-, 58, 1975.

é escassa e o assunto suscita muitas dúvidas pela sua extensão e profundidade.

Considerando estas dificuldades a elaboração deste trabalho tem como objetivos:

- Apresentar uma análise do metabolismo hidrossalino, de maneira sucinta, clara e precisa para facilitar uma visão global do assunto.

- Aplicar os princípios gerais que regulam o metabolismo dos líquidos e eletrólitos orgânicos ao planejamento dos cuidados de enfermagem exigidos pela situação do paciente.

\section{II - ANÁTOMO - FISIOLOGIA DOS LIQUIDOS CORPORAIS}

\section{Distribuição dos Líquidos}

Sabe-se que o corpo humano é constituído por 60 a $70 \%$ de líquidos, sendo o restante representado por gorduras, sais minerais, proteínas e substâncias correlatas.

Os líquidos estão distribuídos em compartimentos. O compartimento intracelular que engloba dois terços do total de líquidos e o extracelular, o restante, compreendendo o intersticial e intravascular.

Líquido intracelular (LIC) - 40 a $50 \%$ Líquido extracelular (LEC) - $20 \%$

- Intersticial ........ - $15 \%$

- Intravascular ....... - $5 \%$

Embora considerados nestas proporções os líquidos corporais estão em constante dinâmica, o que proporciona não somente mudanças de volume do líquido nos compartimentos, como também modificações freqüentes da sua composição, para atender às necessidades instantâneas que se registram na fisiologia ou na presença de quadros patológicos. Considera-se, porém, como de relativa constância o número de eletrólitos existentes no líquido do extracelular, bem como no líquido intracelular.

\section{Composição dos Líquidos}

Os sais minerais dissolvidos nos líquidos orgânicos são substâncias dotadas de carga elétrica, por isto denominadas de eletrólitos ou iontes. Os iontes podem ser: cationtes, os de carga elétrica positiva e os aniontes, os de carga elétrica negativa .

As demais substâncias que constituem os sclutos são substâncias orgânicas.

No LEC predominam o cationte sódio $(\mathrm{Na}+)$ e o anionte cloro $(\mathrm{Cl}-)$. No LIC o cationte predominante é o potássio $(\mathrm{K}+)$ e o anionte o fosfato ( $\mathrm{HPO}--$ ).

Conquanto os líquidos do comportamento extracelular estejam contidos nos vasos e nos espaços intersticiais, bem como nas secreções, os mesmos apresentam uma composição similar.

Para exames laboratoriais o líquido disponível é o extracelular, mais comumente o intravascular, para dosagens de eletrólitos e gases dissolvidos no sangue. Observe-se que no plasma o número de aniontes se equivale ao número de cationtes, ou seja $155 \mathrm{mEq} / 1$ de ambos. A quebra deste equilíbrio leva a distúrbios os mais variados e decorre de circunstâncias intrínsecas e extrínsecas da condição em que se encontre o indivíduo.

Para efeito comparativo é conveniente citar os valores médios normais de eletrólitos plasmáticos.

\section{Eletrólitos plasmáticos}

\section{CATIONTES $\mathrm{mEq} / 1$}

Sódio (predominante) $\ldots \ldots \ldots \ldots 142$

Potássio ................... 5

Cálcio ..................... 5

Magnésio ..................... 3

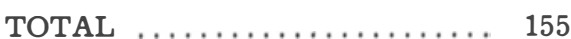


OLIVEIRA, C. - Atuação da enfermeira junto aos pacientes com distúrbios do metabolismo hidrossalino. Rev. Bras. Enf., R.J., 28 : 52-58, 1975.

\section{ANIONTES}

Cloro (predominante) ......... 103

Bicabornato ................ 27

Fosfato ................... 2

Ácidos orgânicos $\ldots \ldots \ldots \ldots \ldots \ldots 6$

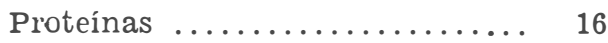

Sulfato .................. 1

TOTAL $\ldots \ldots \ldots \ldots \ldots \ldots \ldots \ldots, 155$

Para manutenção das taxas de eletrólitos e do volume de água em cada compartimento o organismo lança mão de um dispositivo extremamente preciso, que é o fenômeno da osmose. Através da membrana semi-permeável que separa os compartimentos a água passa livremente, necessitando para tanto apenas de mudança na concentração de eletrólitos em um dos lados. Maior concentracão exige a chegada de água para diluir o seu conteúdo, igualando assim a concentração dos dois compartimentos. A osmose se dá portanto mediante um processo que envolve concentração do conteúdo, característica do continente (membrana) e pressão exercida. A esta pressão se chama de pressão osmótica. A pressão osmótica total de uma solução é denominada de osmolaridade e tem como medida o osmol ou o milosmol. Para o controle de toda esta complexa dinâmica de processo encontramse em funcionamento no organismo os sistemas homeostáticos ou reguladores, que são representados pelos aparelhos: cardiovascular, respiratório, urinário e pelas glândulas endrocrinas, principalmente a hipófise, as suprarenais e as parotireoides. Também a pele exerce importante papel nesta regulação, através da maior ou menor perda de água cutânea, conforme condições ambientais e orgânicas, em que se encontre o indivíduo.

A entrada e a saída da água no corpo humano efetuam-se de maneira natural, sem participação voluntária até cer- to limite, visto que as solicitações da ingestão são dadas pela sensação de sede e a eliminação se processa pelos controles hormonais e por um funcionamento renal satisfatório. O problema só é percebido quando alguma das vias de entrada ou saída dos líquidos torna-se desregulada. Em condições fisiológicas o indivíduo adulto ingere o equivalente às perdas, ou seja cerca de $2500 \mathrm{ml}$, sendo assim distribuídos:

\section{Ingestão}

Água em natureza ...... $1.200 \mathrm{ml}$

Água dos alimentos ..... $1.000 \mathrm{ml}$ Água endógena ou por oxi-

dação dos tecidos ....... $300 \mathrm{ml}$ TOTAL .......... $2.500 \mathrm{ml}$

Perda

Urina ................ $1.400 \mathrm{ml}$

Fezes .................. $100 \mathrm{ml}$

Perspiração insensível ... $1.000 \mathrm{ml}$ TOTAL .............2.500 $\mathrm{ml}$

Com esta ingestão igual a eliminação o equilíbrio do balanço hídrico está presente. Diz-se que o balanço é positivo quando a ingestão é superior à eliminação e no caso inverso se registrará o balanço negativo.

A perspiração insensível é calculada segundo alguns autores considerando-se a seguinte fórmula: $0,5 / \mathrm{Kg} / \mathrm{h}$ ou seja $12 / \mathrm{Kg} /$ dia .

Vários fatores, porém, levam ao aumento das necessidades básicas de água e conseqüentemente também de eletrólitos, tais como: intenso calor ambiente, sudorese excessiva, hipertermia, deficit da concentração renal, perdas gastrointestinais e outros.

\section{Medidas utilizadas}

Para o solvente utiliza-se o litro (1) e o mililitro $(\mathrm{ml})$, sendo este último o que mais se emprega para os líquidos 
OLIVEIRA, C. - Atuação da enfermeira junto ass pacientes com distúrbios do metabolismo hidrossalino. Rev. Bras. Enf., R.J., 28 : 52- 58, 1975.

corporais. Para os solutos as medidas são: mol e milimol, grama e miligrama. Como os sais minerais são dotados de carga elétrica não se pode utilizar estas medidas para expressar os seus valores, pois os mesmos diferem em termos de combinação química. Para tal, a medida utilizada toma por base uma grama do $\mathrm{H}+\mathrm{l}$ sendo denominada de equivalente (Eq) e a sua milésima parte de milequivalente (mEq).

\section{III - SITUAÇÕES QUE ENVOLVEM ALTERAÇÕES}

Consideradas as situações anátomofisiológicas dos líquidos corporais notase que há uma constante troca de eletrólitos e água nos compartimentos para que o metabolismo orgânico se verifique satisfatoriamente. Destaca-se também que as modificações são sensivelmente atingidas por qualquer condição que altere a fisiologia orgânica, o que equivale dizer que as alterações hidroeletrolíticas podem ser registradas em todos os quadros patológicos.

Para facilitar a análise podem-se grupar as alterações em:

1. Alterações referentes a água:

- Excesso ou deficit de volume.

- Passagem de água do plasma para o interstício e vice-versa.

2. Alterações referentes aos eletrólitos:

Excesso ou deficit de um ou mais e?etrólitos no plasma.

3. Alterações referentes ao pH do plasma:

- Acidose e alcalose metabólicas.

- Acidose e alcalose respiratórias.

O excesso de água ou hiperidratação verifica-se na administração de doses exageradas de solução salina, na insuficiência cardíaca congestiva, na insuficiência renal e no uso prolongado de corticóides.

$O$ deficit se registra pela falta de ingestão ou pela perda excessiva através de vômitos, diarréias, hipertermia, drenagens e outras.

No tocante aos eletrólitos o excesso ou o deficit provoca modificações da sua concentração nos líquidos corporais, levando ao surgimento de síndromes de hiper ou hipouremia, hiper ou hipopotassemia, hiper ou hipocalcemia e hipoproteinemia, para citar apenas as principais. É indispensável lembrar que geralmente as alterações surgem em cadeia, dificilmente se verificará alteração isolada de água ou de um eletrólito. O que se convencionou chamar de desidratação e de hiperidratação na realidade não são apenas perdas e excessos isolados de água, senão acompanhados de perda ou retenção de eletrólitos, principalmente do sódio.

Para o estudo das síndromes caracterizadas como alcalose e acidose é indispensável considerar o aumento ou diminuição do bicabornato e do ácido carbônico no plasma, o que leva a uma modificação do pH sanguíneo, o qual, fisiologicamente deve-se manter em torno de 7.35 a 7.45. Abaixo e acima das referidas taxas limites considera-se o paciente em acidose ou em alcalose. Estas sindromes estão portanto relacionadas com a concentação de hidrogênio ionte no plasma, por isto a conceituação mais aceita atualmente para ácidos e bases é a de que o primeiro é doador de $\mathrm{H}+$ e o segundo é receptor de $\mathrm{H}+$.

$$
\begin{aligned}
& \mathrm{HCO}_{3}=\text { bicabornato } \\
& \mathrm{H}_{2} \mathrm{CO}_{3}=\text { ácido carbônico }
\end{aligned}
$$

$\mathrm{HCO}_{s}+\mathrm{H}+-$

$\mathrm{H}_{2} \mathrm{CO}_{8}-$

$\mathrm{H}_{2} \mathrm{O}+\mathrm{CO}_{2}$ 
OLIVEIRA, C. - Atuação da enfermeira junto aos pacientes com distúrbios do metabolismo hidrossalino. Rev. Bras. Enf., R.J., 28 : 52- 58, 1975.

Os fatores que concorrem para o equilíbrio do pH são chamados de "sistemas tampões".

Segundo Goldberger (9) “o termo "tampão" designa uma substância química que, pela sua presença numa solução, reduz a modificação do $\mathrm{pH}$ causada pela adição de ácido ou de base. Um tampão é ou a mistura de um ácido fraco e seu sal alcalino ou de uma base fraca e seu sal ácido". Deste modo, os sistemas tampões agem diretamente no plasma, fazendo com que o $\mathrm{pH}$ se eleve no caso da acidose e diminua no caso da alcalose. Em ambos os casos estes sistemas tentam colocar novamente $\mathrm{o} \mathrm{pH}$ dentro dos limites de normalidade. A alcalose ocorre devido ao aumento do bicarbonato $\left(\mathrm{HCO}_{3}\right)$ ou ao deficit de ácido carbônico $\left(\mathrm{H}_{2} \mathrm{CO}_{2}\right)$ no plasma. Há, portanto, aumento de pH plasmático. A acidose se dá quando a situação é inversa: aumento do ácido carbônico ou baixa de concentração de bicarbonato com conseqüente baixa do $\mathrm{pH}$ plasmático.

\section{IV - ASPECTOS DA ATUAÇÃO DA ENFERMAGEM}

Uma observação sistemática deve ser feita pela enfermeira, conhecendo os aspectos anteriormente analisados para que o mais precocemente possível se detecte qualquer alteração no paciente.

Comumente utiliza-se a anotação das perdas e ingestão ou administação de líquidos em folhas especiais de controle, as quais variam quanto à forma em cada serviço mas de um modo geral contém os itens essenciais para se estabelecer o balanço hídrico diário do doente. É importante lembrar que este controle deve fazer parte do plano de assistência de enfermagem do paciente, o que resulta dizer que a enfermeira avaliará a necessidade apresentada pelo quadro do mesmo, para que se solicite da equipe a realização do controle de líquidos. O conhecimento do tipo de líquido perdido é condição indispensável para numa eficiente reposição de eletrólitos. Embora através de exames laboratoriais sejam registradas, com precisão, as taxas representativas do deficit ou elevação de concentração de alguns elementos plasmáticos, este recurso não dispensa uma efetiva observação clínica da enfermeira.

Esta observação clínica se dá atravéó da:

- Verificação da condição da pele do paciente, que fornecerá dados quanto ao estado de hidratação.

- Circulação superficial dos membros superiores, cujos vasos normalmente se esvaziam quando o braço está elevado e enchem-se quando o braço está pendente. Na desidratação grave há lentidão no enchimento e na hiperidratação há engurgitamento.

- Controle de sinais vitais. A temperatura eleva o gasto líquido e energético. Cada grau de temperatura acima de $37^{\circ} \mathrm{C}$ corresponde a uma perda líquida de $150 \mathrm{ml}$ em 24 horas. A hiperpnéia leva à niaior perda de água, bem como, pode ser representativa de uma compensação da acidose metabólica. O pulso pode traduzir alterações referentes ao deficit de volume líquido extracelular ou do bombeamento cardíaco através de modificações na freqüência, regularidade e volume. A pressão arterial é um índice indicativo de quase todas as alterações dos líquidos e eletrólitos, principalmente de deficiência de sódio plasmático, queda do volume sanguíneo total, maior ou menor concentração de potássio, quando se registra hipotensão. A hipertensão é um dado referido para excesso de volume plasmático e deficit de magnésio.

- Tipo de dieta ingerida pelo paciente ou abstenção da ingestão.

- Administração de líquidos e eletrólitos por via parenteral. Neste caso 
OLIVEIRA, C. - Atuação da enfermeira junto aos pacientes com distúrbios do metabolismo hidrossalino. Rev. Bras. Enf., R.J., 28 : 52- 58, 1975.

toma-se em consideração, idade, estado nutricional, condições clínicas apresentadas pelo paciente e as perdas registradas. Atenção especial se faz necessária para a velocidade de gotejamento, tipo de solução presente, distribuição do volume para o tempo previsto de administraão e reações verificadas.

- Presença de edema, ascite e ileo intestinal, que denotam seqüestro do líquido, o qual não entrará no metabolismo.

- Presença de drenos, o que exige do volume e tipo de líquido perdido.

- Referência do paciente a sensação de sêde ou de fome.

- Presença de vômitos, diarréia, aspiração gastrointestinal, traqueostomia, fístulas ou qualquer outra via de perda de água e de eletrólitos.

- Conduta do paciente, que pode sofrer transformação face às alterações metabólicas, principalmente quando se trata de ancião.

- Controle de função renal. Volume c̉e excreção urinária, densidade, $\mathrm{pH}$, cor, aspecto e queixa do paciente referente à alteração na eliminação.

Estas verificações fornecerão os dados necessários para o diagnóstico e planejamento da assistência de enfermagem.

\section{$\mathrm{V}-$ CONCLUSÃO}

Observa-se que a mecânica dos líquidos corporais dá-se continuamente, num sábio processo natural de demanda das necessidades fisiológicas do indivíduo. É imprescindível, porém, que o organismo esteja isento de agressões exógenas e endógenas. Face a qualquer agressão, seja traumatológica, cirúrgica ou levada por afecções pré-instaladas, a resposta se faz sentir com a quebra da homeostasia e o surgimento das alterações metabólicas.

Face a estas alterações o desempenhc da enfermagem junto ao paciente, diagnosticando precocemente as alterações, assegura um eficiente controle, o que leva a um esquema de segurança quanto ao tratamento e retorno do equilíbrio dos sistemas que levarão ao restabelecimento da homeostase.

\section{BIBLIOGRAFIA}

1. BEVILACQUA, F. et alii - Manual de fisiopatologia clínica. Rio de Janeiro, Atheneu, p. 572-93, 1971.

2. BRUNNER, L. S. et alli - Transtornos de líquidos corporales: In: Enfermeria medicoquirurgica. 2. ed. Mexico, Interamericana, p. 77-92, 1971. ,

3. CICONELLI, M, I, R. \& CICONELLI, A. J. - Balanço hídrico e eletrolítico em cirurgia. R. Bras. Enf. 17 (3-4) : 90-98, jun -ago. 1964.

4. CORREA NETTO, A. - Clínica cirúrgica. 2 ed. São Paulo, Servier, p. 109-24, 1968.

5. DAVIS, L. ed. - Clínica cirúrgica. 2 ed. Rio de Janeiro, Guanabara Koogan, p. 77-94, 1970.
6. DOWING, S. H. - Nursing support in early renal farlure. Amer. J. Nurs. 69 (6): 1212-6, Jun. 1969.

7. F'ERNANDES, N. L. - Alterações ácido-básicas na parada cardíaca. $\mathbf{R}$. Med. IAMPSE 1 (2) : 87-96, abr.jun. 1970.

8. FERREIRA, J. R. et alii - controle hidro - eletrolítico e ácido - básico em cirurgia. In: Controle clinico do paciente cirúrgico 3 . ed. Rio de Janeiro, Atheneu, p. 85-138, 1969.

9. GOLDBERGER, E. - Alterações do equilíbrio hídrico e ácido - básico. 3. ed. Rio de Janeiro, Guanabara Koogan, 394p. 1969.

10. GONÇALVES, E. L. - Metabolismo e 
OLIVEIRA, C. - Atuação da enfermeira junto aos pacientes com distúrbios do metabolismo hidrossalino. Rev. Bras. Enf., R.J., 28 : 52- 58, 1975.

cirurgia. São Paulo, Servier, 244p ilus, 1973.

11. GRANT, J. A. et alii - Parenteral hyperalimentation. Amer. J. Nurs. 69 (11): 2392-5, Nov. 1969.

12. HABERICH, F. J. - Papel dos receptores osmóticos do sistema porta na regulação do equilíbrio lúdrico. Triângulo 10 (4): 123-30, 1972.

13. HATCHER, J. - Plasma electrolytes and flame phctometry. Nurs. Mirror 136:38-9, Feb. 1973.

14. KINNEY, I. M. et alii - Tratamiento pre y posoperatorio. Mexico, Interamericana, p. 42-75, 1973.

15. MAKSOIJD, J. G. - Alterações da composição hidroeletrolítica de tecido no pós-operatório. R. Assoc. Med. Bras. 17 (8) : 279-82, ago. 1972.

16. METHENY, N. M. \& SNIVELY, W. D. - Terapeutica de líquidos y electrolitos. Mexico, Interamericana, 272p. ilus, 1970.

17. O. - Terapêutica. Rio de Janeiro, Atheneu, p. 572-93, 1971.

18. MUTTON, C. J. - The management of intravenous infusions. Nurs. Times 69: 701-2, May 31. 1973.

19. PEREIRA NETTO, M. \& REGO, J. D. - Visão prática dos componentes do equilíbrio ácido-básico. J. Pediat. 34 (9-10): 201-7, set.-out. 1969.

20. PICTON. S. J. et alii - A difficult case of fluid management. Nurs. Times 64: 1485-8, 1 Nov. 1968.

21. RANDALL, H. T. - Terapeutica hidrica e eletrolítica. In: Manual de cuidados pré e pós-operatórios. Rio de Janeiro, Guanabara Koogan, p. 15-52, 1969.
22. ROTELLAR, E. - ABC dos transtornos eletrolíticos. Rio de Janeiro, Atheneu, 221p. ilus., 1968.

23. ROTELLAR, E. - Transtornos electrolíticos más frecuentes. Barcelona, Ed. Jimes, 1970.

24. SHARER, J. E. - Reviewing acidbase balance. Amer. J. Nurs. 75 (6) : 980-3, Jun. 1975.

25. SHOEMAKER, W. C. \& WILKER, W. F. - Tratamiento de enfermedades agudas con liquidos y electrolítos. Mexico, Interamericana, 1970.

26. SIEGEL, P. D. - Enfoque fisiológico del equilibrio acido básico. Clínicas Médicas do Norte America, 8: 6380, Jul. 1973.

27. SILVA, J. A. F. et alii - Alteracões do equilíbrio ácido-base em hepatopatias. O Hospital 76 (3): 32735, set. 1969 .

28. SMITH, D. W. et alii - Regulacion de agua y electrolitos. In: - Enfermeria Medicoquirurgica. 3. ed. Mexico, Interamericana, p. 83-89, 1973.

29. SOUZA, C. A. M. \& ALVES JUNIOR, A. R. - Distúrbio do equilíbrio hídrico e eletrolítico. Bol. Inf. ASSER 4 (16): 21-39, jul-set. 1967.

30. _ / Distúrbios do equilíbrio hídrico e eletrolítico; 2. Diagnóstico e tratamento Bol. Inf. ASSER 5 (17), 9-30, out.-dez. 1967.

31. TAYIOR, W. H. - Alteraciones del balance hidroelectrolítico y su tratamiento. Barcelona, Toray, 1972.

32. VODA, A. M. - Bocly Water dynamies: a clinical application. Amer. J. Nurs. 70 (12) : 2594-601, Dec. 1970. 